Araştırma / Research

\title{
KENTSEL BÜYÜME İLE MOTORLU ARAÇ TRAFİĞİ YOĞUNLUĞU ARASINDAKİ İLIŞSİNIN BELİRLENMESI: İSTANBUL ÖRNEĞİ
}

\author{
Zeynel Abidin POLAT (ORCID: 0000-0002-4127-3705) ${ }^{1^{*}}$ \\ Abdulkadir MEMDUHOĞLU (ORCID: 0000-0002-9072-869X) ${ }^{2}$ \\ Müslüm HACAR (ORCID: 0000-0002-8737-8262) ${ }^{1}$ \\ Hüseyin DUMAN (ORCID: 0000-0002-7340-7800) ${ }^{1}$ \\ ${ }^{I}$ Harita Mühendisliği Bölümü, İnşaat Fakültesi, Yıldız Teknik Üniversitesi, Istanbul, Türkiye \\ ${ }^{2}$ Harita Mühendisliği Bölümü, Mühendislik Fakültesi, Harran Üniversitesi, Şanlıurfa, Türkiye
}

\author{
Gelis / Received: 27.12 .2016 \\ Düzeltmelerin gelişi / Received in revised form: 15.05.2017 \\ Kabul / Accepted: 16.05.2017
}

\begin{abstract}
ÖZ
Bu çalışmada 2005-2014 yılları arasında kentsel büyümeye bağlı olarak artan konut sayısının ana ulaşım ağında yarattığ 1 trafik yoğunluğu ilişkisi İstanbul özelinde incelenmiştir. Bu amaçla İstanbul'da kentsel büyümenin yoğun olarak görüldüğü ilçeler (Konut bölgeleri) ile bu ilçeleri etkileyen ana ulaşım hatları belirlenmiştir. Geleceğe yönelik tahmin modellerinde kullanılabilen konut sayısı ile trafik yoğunluğu arasındaki ilişkiyi belirlemek amacıyla regresyon analizi yapılmış ve korelasyon katsayıları hesaplanmıştır. Analizler neticesinde, Avrupa yakasında özellikle Büyükçekmece, Beylikdüzü, Esenyurt ve Avcılar ilçelerindeki kentsel büyümeye bağlı olarak artan konutlaşmanın beraberinde trafik yoğunluğunu da getirdiği gözlemlenmektedir. Anadolu yakasında ise Sultanbeyli, Pendik ve Tuzla ilçelerinde son y1llardaki artan konutlaşmaya bağlı olarak bu ilçeleri etkileyen ana ulaşım hatlarında trafik yoğunluğunda artış olduğu gözlemlenmektedir. Konut bölgelerinde gelecekteki trafik yoğunluğun tahmin edilebilmesi için gereken denklemler regresyon analizi sonucu elde edilmiştir.
\end{abstract}

Anahtar Kelimeler: Kentsel büyüme, trafik yoğunluğu, korelasyon, regresyon analizi

\section{DETERMINING THE RELATIONSHIP BETWEEN URBAN GROWTH AND MOTOR VEHICLE TRAFFIC: ISTANBUL CASE STUDY}

\begin{abstract}
In this study, the traffic density relations in the main transportation network of Istanbul occurred from the increasing number of housing as a result of urban growth are examined. In this respect, the districts (residential zones) where urban growth is dense and the main transportation lines serving these districts have been determined. Regression analysis has been utilized in order to detect the relation between the number of residential properties used for future forecast models and traffic. Also, correlation coefficients have been calculated. As a result of the analysis, it is observed that the traffic density has been affected by the residential development due to urban growth especially in the districts of Büyükçekmece, Beylikdüzü, Esenyurt and Avcılar in the European side of Istanbul. In the Asian side, increased residential development in Sultanbeyli, Pendik and Tuzla districts causes heavy traffic in the main transportation lines serving these districts. The equations necessary for determining the future traffic density in these residential areas have been obtained by regression analysis.
\end{abstract}

Keywords: Urban growth, traffic density, correlation, regression analysis

*Corresponding author / Sorumlu yazar. Tel.: +90 543639 7402; e-mail / e-posta: zapolat@ yildiz.edu.tr 


\section{GíRiș}

Kentsel büyüme ve ulaşım birbiriyle etkileşim içinde bulunan ve birbirlerini izleyen, ancak olgu ve etki-tepkikontrol mekanizmaları açısından birbirinden tamamen farklı, insan faaliyetleridir [1]. Nüfus artışı ve büyük çaplı göçlerin etkisiyle [2] ortaya çıkan kentsel büyümeye bağlı olarak çevresel, ekonomik [3, 4], sosyal [5] ve ulaşım alanlarında günlük yaşamı etkileyen bazı değişimler meydana gelmektedir. Kentsel büyüme ile birlikte ulaşımda meydana gelen değişimler, ekonomik, psikolojik, sağlık ve zaman açısından insan üzerinde önemli bir etki yaratmaktadır. Kent içinde yaşanan ulaşım sorunu mevcut arazi kullanımı ve konut yapısı ile doğrudan ilgilidir [6]. Arazi kullanımı ile ulaşım arasındaki etkileşim kendi içinde bir döngüye sahiptir. Ulaşım altyapısının gelişimi kişilerin erişimini kolaylaştırır ve yeni yaşam alanlarının oluşumunu tetikler. Yeni yaşam alanlarının oluşumu ise çevrede gerçekleştirilecek alt yapı çalışmaları ve ekonomik faaliyetlerin gelişimiyle yeni ulaşım hizmetlerinin gerekliliğini ortaya çıkarır [7]. Kentleşme ve ulaşım ağlarının birbirinden bağımsız olarak düşünüldüğü çalışmalar, telafisi zor sonuçlar doğurmaktadır [8]. Bu bağlamda aralarındaki ilişki arazi kullanım planlarıyla uyumlu, kentsel gelişmeyi destekleyici nitelikte ve etkin bir kent içi ulaşım hedefiyle ele alınmalıdır. Gelecekte oluşacak muhtemel ulaşım taleplerinin karşılanmasına yönelik ilke, hedef, strateji, yaklaşım ve politikalar geliştirilmesi ideal bir ulaşım sisteminin uygulanması için kaçınılmazdır [9]. Sürdürülebilir bir kentsel planlamaya bağlı olarak ideal bir ulaşım sisteminin olmadı̆̆ı kentsel bölgelerde düzensiz konutlaşma faaliyetleri giderek artmaktadır. Yetersiz altyapı ve toplu ulaşıma bağlı olarak konut sahiplerinin kendi araçları ile ulaşımını sağlamaları mevcut trafik sıkışıklığını daha da artırmaktadır. Bu durum ulaşım maliyetini artırırken zaman kaybına da sebep olmaktadır. Fırat [10]'a göre ulaşım sorununun temelinde plansız gelişme, hızlı nüfus artışı ve göç yatmaktadır. Toprak ve Aktürk [11] ise artan nüfus, işgücü ve trafikteki araç sayısının ulaşım sorununu tetiklediğini vurgulamaktadır.

Kentleşme 1950'lerden beri dünyada hızla artmaktadır. Türkiye'de ise kentleşme 1980'lerden sonra ivme kazanmıştır [12]. Kırdan kente göçlerin en yoğun olarak yaşandığı şehirlerin başında İstanbul gelmektedir. Sahip olduğu nüfus potansiyeline bağlı olarak sürekli büyümekte olan İstanbul, barınma, beslenme, ulaşım gibi temel ihtiyaçlara cevap vermekte yetersiz kalmaktadır. Özellikle yetersiz ulaşım altyapısına bağlı olarak meydana gelen \%58'lik trafik yoğunluğu ile 2015 yılı itibari ile dünya genelinde ilk sıradadır [13]. İstanbul'daki aşırı trafik yoğunluğunun azaltılması için arazi kullanımı ile doğrudan ilişkili ve İstanbul'a özgü koşulları da dikkate alan sürdürülebilir bir ulaşım planlamasına ihtiyaç vardır. Bu bağlamda ihtiyaç duyulan ideal ulaşım planını hazırlamak için trafik yoğunluğunun sebeplerinden biri olan düzensiz konutlaşmanın mevcut durumunun iyi analiz edilmesi gerekmektedir [36]. Bu amaçla İstanbul Büyükşehir Belediyesi tarafından Mayıs 2006'da İUAP olarak adlandırılan İstanbul Metropoliten Alanı Entegre Kentsel Ulaşım Ana Planı çalışmasına başlanmış ve Japonya Uluslararası İşbirliği Ajansı (JICA) ile teknik işbirliği sağlanmıştır. Yapılan toplantılar ve değerlendirmeler sonucunda İstanbul Ulaşım Ana Planı revizyon çalışmaları Haziran 2009'da başlamıştır.

Kentsel trafik yoğunluğunu oluşturan birçok etken olmaşna karşın bu çalışmada İstanbul'da Silivri, Büyükçekmece, Avcılar, Beylikdüzü, Esenyurt, Bağcılar, Başakşehir, Küçükcekmece, Ümraniye, Sancaktepe, Çekmeköy, Sultanbeyli, Pendik ve Tuzla ilçelerindeki artan konut sayısının ana ulaşım ağlarında yarattığı trafik yoğunluğu ele alınmıştır. Konut sayısının motorlu araç trafiğine olan etkisini belirleyebilmek için 2005-2014 yılları arasındaki veriler analiz edilmiş ve aralarındaki ilişki regresyon analizi sonucu ortaya konmuştur. Çalışma bölgesindeki ilçelere ait konut sayıları Türkiye İstatistik Kurumu'nun (TUİK) web sayfasındaki konut istatistiklerinden derlenmiştir. Bu çalışma bölgeleri etkileyen ulaşım hatlarındaki motorlu araç sayıları ise Kara Yolları Genel Müdürlüğü’nün (KGM) her yıl yayınladığı "Trafik ve Ulaşım Bilgileri” adlı raporlardan derlenmiştir. Kentsel büyüme ile ulaşım arasındaki ilişki belirlemeye yönelik analiz sonuçlarına göre Avrupa yakasında özellikle Büyükçekmece, Beylikdüzü, Esenyurt ve Avcılar ilçelerindeki kentsel büyümeye bağlı olarak artan konutlaşmanın beraberinde trafik yoğunluğunu da getirdiği gözlemlenmektedir. Anadolu yakasında ise Sultanbeyli, Pendik ve Tuzla ilçelerinde son yıllardaki artan konutlaşmaya bağlı olarak bu ilçeleri etkileyen ana ulaşım hatlarında trafik yoğunluğunda artış olduğu gözlemlenmektedir.

\section{KENTSEL BÜYÜME VE ULAŞIM}

İnsan ve çevre arasındaki mekânsal etkileşimin en iyi şekilde gerçekleştiği kentsel alanlar, dinamik özellikteki yerler olup, kentsel nüfusun artışına paralel olarak mekânsal alanı genişlemekte ve görünümü değişmektedir [14]. Kentlerdeki nüfus artışının yarattığı dinamizme bağlı olarak barınma ve ulaşım talepleri hızla artmaktadır. $\mathrm{Bu}$ açıdan kentleşme tarihi incelendiğinde, nüfus artışı kentlerin büyümesinin ana sebebi olmuştur [15]. Tarihsel süreçte, üretim biçimindeki değişimlere bağlı olarak tüm dünyada kentlerin nüfusu artmış ve 1900'lü yıllarda dünya nüfusunun \%9'u kentsel alanda yaşarken, bu oran 1980'de \%40'a, 2000'de ise \%50'ye çıkmıştır. Bu oranın 2025'de \%66'ya çıkacağı öngörülmektedir [16]. Tosun'a [17] göre kentsel büyüme; motorlu araç 
kullanımını artırması, çevresel kalitenin bozulması, gürültü, yaşam kalitesi düşüklüğü ve sosyal ayrışma gibi olumsuz sonuçlar doğurmuştur.

Günümüzde metropoliten kentlerin genişlemesi kentsel yayılma (urban growth) modeli ile açılanmaktadır [2, $4,13,18,19]$. Kentsel büyüme, fiziksel, çevresel ve sosyo-ekonomik nedenlere bağımlı olduğu için dinamik, doğrusal olmayan ve kompleks bir yapıya sahiptir ve karmaşı sistem teknikleri ile modellenebilmektedir [2023]. Modelleme sonuçlarına göre Ewing ve ark. [24] kentsel yayılmanın ortaya çıkardığı etkileri dört farklı boyutta ele almaktadır [15];

- Nüfusun seyrek yapıllaşmayla dağılması,

- Konutların, işyerlerinin ve ticaret merkezlerinin birbirinden uzakta ve keskin sınırlarla ayrılması,

- Yol ağının büyük bloklarla ve zayıf erişilebilirlikle belirginleşmesi,

- Güçlü bir kent merkezinin olmamasıdır.

Geriye kalan diğer farklı durumlar ise yayılma ile paralel gelişmektedir. Bunlar, ulaşım seçeneklerinin yetersizliği, konut alanlarında göreceli monotonluk veya yürüyerek ulaşım olanağının azalması gibi yukarıdaki durumların ortaya çıkardığı sonuçlardan oluşmaktadır [24].

Kentsel büyümenin büyüklüğünü etkileyen en temel etmenlerden biri o kentsel bölgedeki ulaşım talebidir [4]. Arbury [25] çalışmasında son 200 yıllık periyotta ulaşım türünün değişiminin kentsel alandaki yayılmaya etkisini incelemiştir (Şekil 1). Çalışmaya göre kentsel yayılmanın ortaya çıktığı ilk dönemlerde, kentsel yayılma alanı tren veya tramvay güzergâhlarına bağlı olarak ve sınırlı bir gelişme gösterirken, otomobilin kent yaşamına girmesi ile birlikte bu sınırlamayı aşmıştır [15]. Akseki ve Meşhur [15] bu durumun düşük yoğunluklu konut alanlarının doğuşuna ve kentsel fonksiyonların birbirinden ayrılmasına da (desantralizasyon) neden olan otomobilin, raylı sistemlere göre oldukça farklı bir yerleşme deseninin ortaya çıkışına neden olduğunu vurgulamaktadır.

Trafik tıkanıklığının nedeni genelde kent içi ulaşımda özel araç kullanma eğilimindeki artışlardır. Bu eğilimin artmasının, toplu ulaşım sistemindeki yetersizlikler, özel aracın sağladığı konfor ve rahatlık gibi birçok nedeni vardır [26, 27].

Kentin büyümesiyle ilgili, gelecek yıllar için kent sınırlarının nerelere ulaşacağı, konut amaçlı arazi kullanımına bağlı olarak trafik yoğunluğunda meydana gelen ve gelecek değişimlerin belirlenmesi ve önceden kestirilebilmesi büyük önem arz etmektedir.
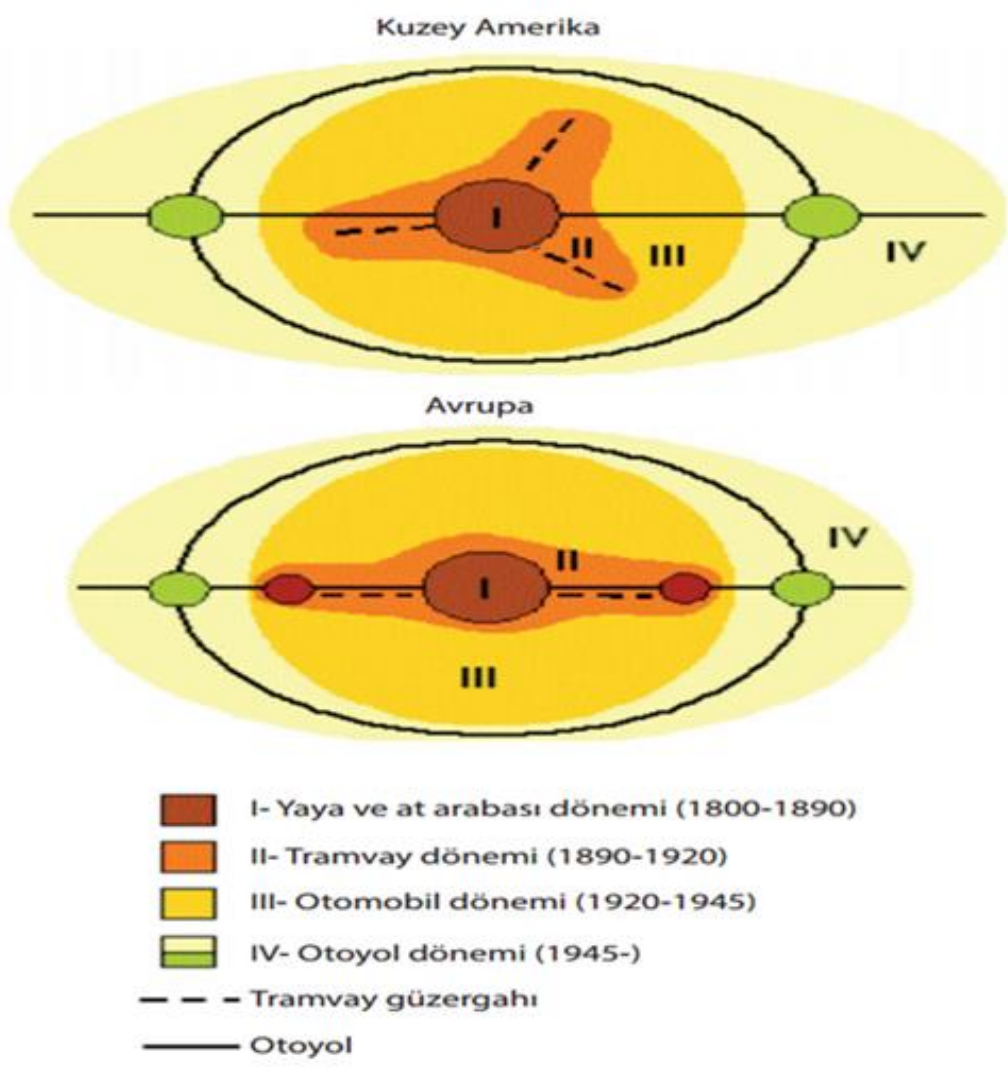

Şekil 1. Ulaşım biçiminin kent makroformuna etkisi [15, 25]. 


\section{3. ÇALIŞMA ALANI: İSTANBUL}

İstanbul, Türkiye'nin en kalabalık, ekonomik ve sosyo-kültürel açıdan en önemli şehridir. Şehir, nüfus açısından belediye sınırları göz önüne alınarak yapılan sıralamaya göre Avrupa'da birinci, dünyada ise beşinci sırada yer almaktadır [28]. İstanbul'un 14'ü Anadolu Yakasında, 25'i Avrupa Yakasında olmak üzere toplam 39 ilçesi vardır. Mevcut potansiyelleri ve jeopolitik konumundan dolayı İstanbul, sürekli göç almakta ve nüfusu sürekli artmaktadır (Şekil 2).

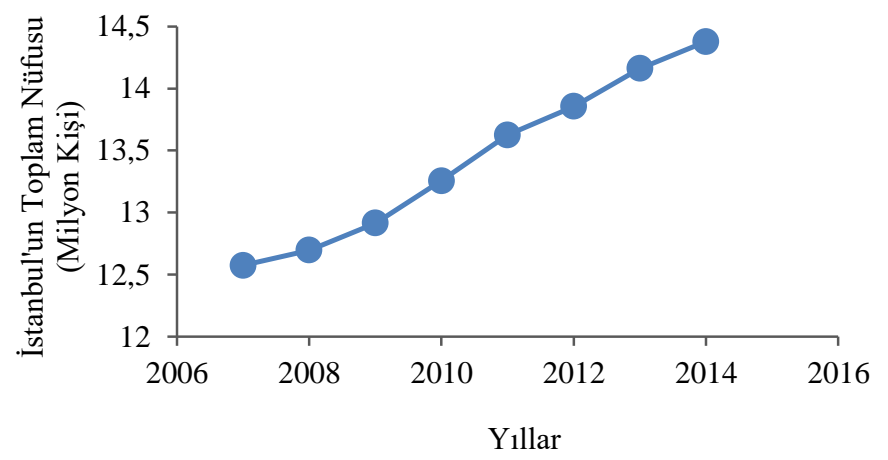

Şekil 2. Yıllara göre İstanbul'un nüfus artış1

TUİK 2014 yılı istatistiklerine göre İstanbul'daki 14,4 milyonluk nüfusu oluşturan yaklaşı1k 3,9 milyon hane vardır [35]. Nüfus artış hızına bakıldığında bu miktar yaklaşık olarak yılda 250 bin kişiye karşılık gelmektedir. Gelişen refah düzeyine paralel olarak nüfusun konut talebi de artmıştır. Yoğun yapılaşma beraberinde ulaşım problemini de getirmiştir. Şehrin doğu ve batı ucunu birbirine bağlayan ulaşım ihtiyacının büyük bir kısmını sağlayan TEM otoyolu ve E-5 (D-100) karayolu yetersiz kalmaktadır. Bu yollar çevresinde yoğunlaşan büyük konut projeleri, alışveriş merkezleri ve hastanelerin getireceği trafik yükü hesaba katılmadığından dolayı trafik yoğunluğuna neden olmaktadır [29]. Metro veya metrobüs gibi toplu taşıma projeleri trafik problemini kısmen giderse de sorunun tamamen çözülmesinde etkili olamamaktadır.

Kentleşme amaçlı arazi kullanımı ve ulaşım birbirleriyle iç içe geçmiş iki yapıdır [1] ve kendi içlerinde bir kısır döngüye sahiptirler (Şekil 3). Ulaşım ağlarının gelişimi kişilerin erişimini kolaylaştırır ve yeni yaşam alanlarının oluşumunu tetikler; yeni yaşam alanlarının oluşumu ise çevrede gerçekleştirilecek alt yapı çalışmaları ve ekonomik faaliyetlerin gelişimi ile yeni ulaşım hizmetlerinin gerekliliğini ortaya çıkarır [7].

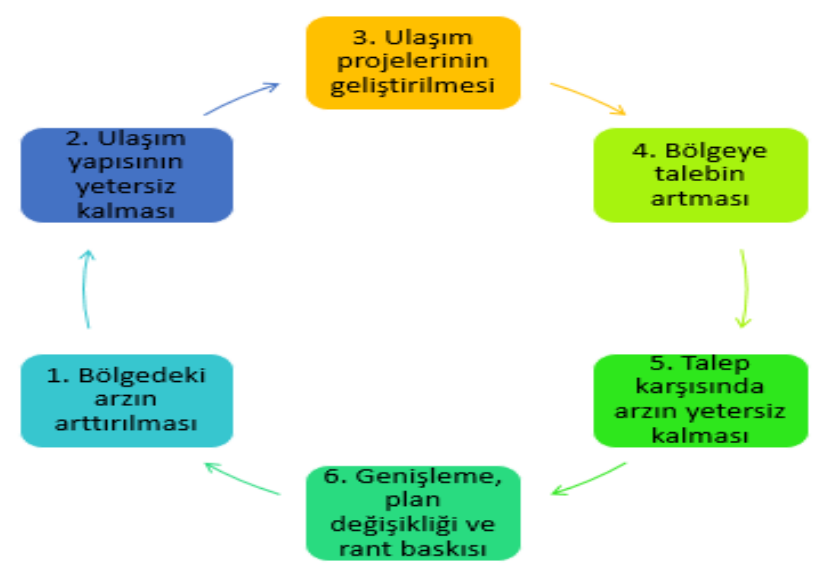

Şekil 3. Ulaşım ve arazi kullanımı arasındaki etkileşimin boyutları ([9]'dan derlenmiştir)

Bugüne kadar uygulanan yanlış kentsel politikalar ulaşım ve arazi kullanım arasındaki etkileşimi olumsuz yönde etkileyerek İstanbul'un en büyük ve en güncel sorunlarından biri olan trafik sıkışıklığını ortaya çıkarmıştır [28]. Türkiye'de 2015 yılı Ekim ayı itibari ile trafiğe kayıtlı araç sayısı 19.793.995'tir [31]. Bu sayının yaklaşık 
\%18'i (yaklaşık 3,5 milyon motorlu araç) ise İstanbul'da kayıtlıdır. Bu derece fazla motorlu aracın yarattığ trafik sıkışıklığına bağlı olarak ortaya çıkan zaman ve işgücü kayıpları ile fazla yakıt tüketimi ekonomiyi olumsuz etkilemektedir. İstanbul Büyükşehir Belediyesi'nin 2013 yılında hazırladığı rapora göre İstanbul'da yılda araç başına 5 depo yakıt boşa harcanmakta; bunun maliyeti ise 5,5 milyar lirayı geçmektedir. Okulların açılmasıyla birlikte artan trafik yoğunluğuna olumsuz hava şartları da eklenince, vatandaşlar 15 kilometrelik bir yol için 1,5 saatten fazla zamanlarını yolda geçirmektedirler [32].

$\mathrm{Bu}$ çalışmada artan konut sayısının ana ulaşım ağlarında yarattığı trafik yoğunluğunu belirleyebilmek ve gelecek için kestirimde bulunabilmek için İstanbul'un ana ulaşım ağına yakın ve konut sayısı bakımından hızlı gelişen bölgeler seçilmiştir. Seçilen konut bölgeleri ve etkilediği ana ulaşım hatları Tablo 1'de listelenmiştir. Konut bölgeleri ve ana ulaşım hatlarının bulunduğu çalışma alanı Şekil 4'teki harita ile sunulmuştur.

Tablo 1. Seçilen konut bölgeleri ve bu bölgeleri etkileyen ulaşım hatları

\begin{tabular}{|l|c|}
\hline \multicolumn{1}{|c|}{ Konut Bölgesi } & Konut Bölgesini Etkileyen Ana Ulaşım Hattı \\
\hline Silivri & Silivri - Selimpaşa \\
\hline Büyükçekmece & Selimpaşa-Kumburgaz-Çatalca-Hadımköy \\
\hline Avcılar-Beylikdüzü-Esenyurt & Hadımköy-Avcılar \\
\hline Bağcılar-Başakşehir-Küçük Çekmece & Avcılar -Mahmutbey \\
\hline Ümraniye-Sancaktepe-Çekmeköy & Çamlıca-Samandıra \\
\hline Sultanbeyli-Pendik & Samandıra-Kurtköy \\
\hline Tuzla & Kurtköy-Şekerpınarı \\
\hline
\end{tabular}

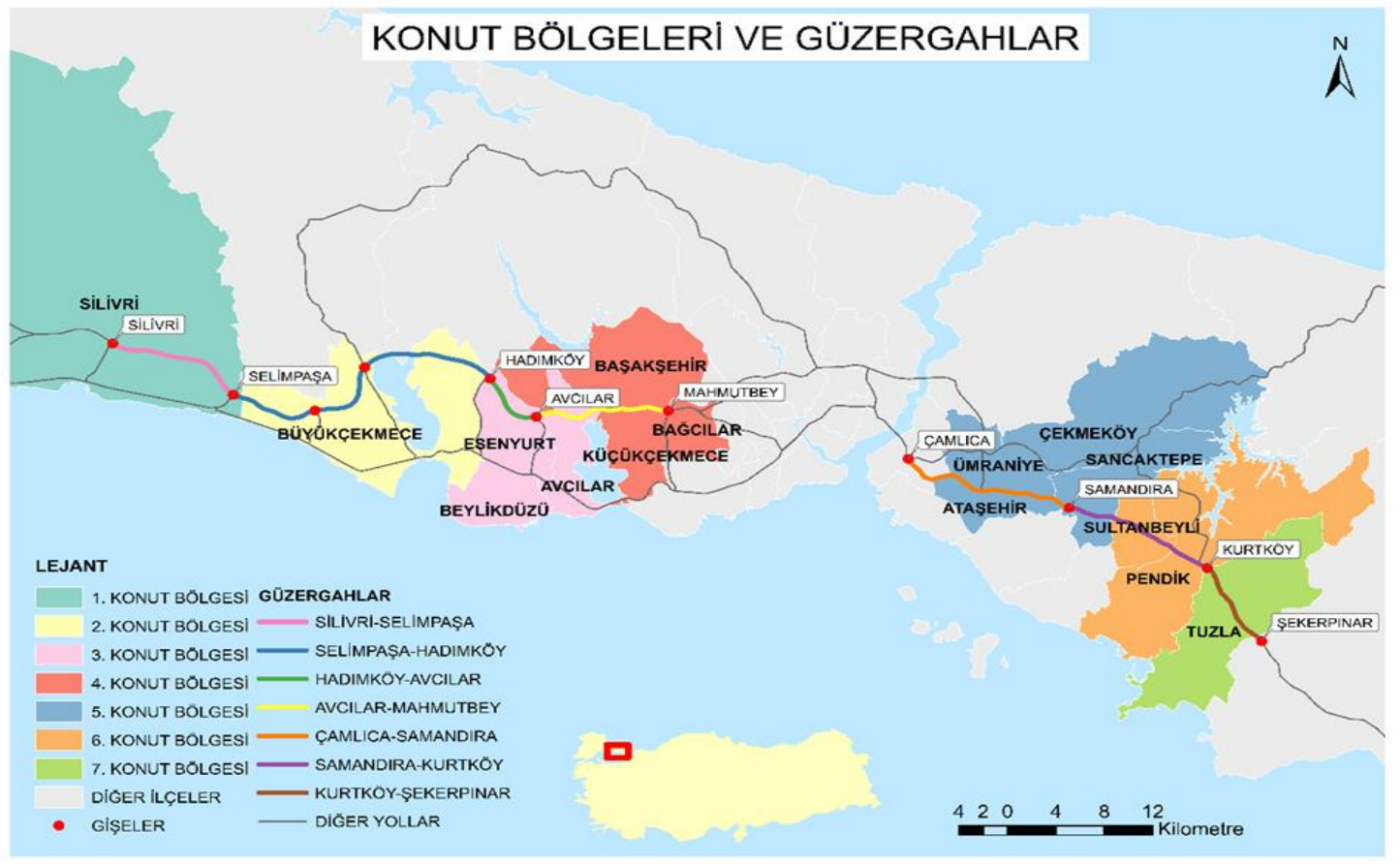

Şekil 4. Konut bölgeleri ve ana ulaşım hatlarının gösterildiği çalışma alanı

\section{MATERYAL VE METOT}

Çalışma kapsamında 2005-2014 yılları arasında İstanbul'a ait yapı kullanım izni alınmış konut istatistikleri ile trafik ulaşım bilgileri kullanılmıştır. Bu istatistikler Türkiye İstatistik Kurumu'ndan (TÜİK) temin edilmiştir. Bölgeleri etkileyen ulaşım güzergâhına ait trafik yoğunluğu değerleri ise Karayolları Genel Müdürlüğü'nün her yıl yayımladığı trafik ulaşım bilgileri indeksinden derlenmiştir [33].

Yapılan modelleme çalışmasında, konut artışının motorlu araç trafiği ile olan ilişkisi regresyon analizi ile belirlenmiş, aralarındaki korelasyon katsayıları (1) eşitliğine göre kestirilmiştir. Bu ilişkiden yola çıkarak 
gelecekteki trafik yoğunluğunu belirleyebilmek amacıyla gerekli parametreler hesaplanmıştır. Modelleme yaklaşımı olarak doğrusal fonksiyon kullanılmıştır.

Regresyon, iki ya da daha çok değişken arasında ilişki olup olmadığını, ilişki varsa yönünü ve gücünü ortaya koyan bir analiz yöntemidir. Regresyon analizinde, bağımsız değişkenlerle uygun bir model parametreleri kestirilerek, geleceğe yönelik olaylarla ilgili tahminler yapılması mümkündür [34].

Korelasyon katsayısı iki değişken arasındaki doğrusal ilişkinin derecesini ölçen bir değerdir ve -1 ile +1 arasında değişir. -1 'e yakın olması, bu değişkenler arasında çok güçlü negatif doğrusal ilişki olduğunu, +1 'e yakın olması da çok güçlü pozitif doğrusal ilişki olduğunu, 0 olması ise aralarında herhangi bir ilişkinin olmadığını işaret eder. $\mathrm{R}^{2}$ belirlilik katsayısı, korelasyon değerinin karesel ifadesi olup bağımsız değişken ile doğrusal model arasındaki uyuşumu, aynı zamanda bağımlı değişken için tahmin kalitesini göstermektedir. Bu değerin 1'e yakınsaması uyuşum ve kalitenin yüksek olduğu anlamına gelmektedir.

Korelasyon katsayısı (r),

$$
r=\frac{n \cdot\left(\sum x \cdot y\right)-\left(\sum x\right) \cdot\left(\sum y\right)}{\sqrt{n \cdot\left(\sum x^{2}\right)-\left(\sum x\right)^{2}} \cdot \sqrt{n \cdot\left(\sum y^{2}\right)-\left(\sum y\right)^{2}}}
$$

eşitliğiyle hesaplanır (Eşitlik 1). Burada $x$ ve $y$ değişkenleri simgelerken, $n$ ise ölçü sayısıdır. Regresyon analizinde iki (basit regresyon) veya daha fazla değişken (çoklu regresyon) arasındaki ilişkiyi açıklamak için doğrusal bir fonksiyon kullanılır. Bu fonksiyon,

$$
Y=\alpha+\beta . X+\varepsilon
$$

eşitliği ile temsil edilir (Eşitlik 2). Burada, $X$ bağımsız ve $Y$ bağımlı değişkenler olup, $\alpha X^{\prime}$ 'in sıfır olması durumunda $Y$ 'deki kesişim, $\beta$ fonksiyonun eğimi ya da regresyon katsayısı ve $\varepsilon$ rastgele hataları temsil etmektedir.

$$
\beta=\frac{\sum\left(x_{i}-\bar{x}\right)\left(y_{i}-\bar{y}\right)}{\sum\left(x_{i}-\bar{x}\right)^{2}} \quad \alpha=\bar{y}-\beta(\bar{x})
$$

Regresyon katsayısı $(\beta)$ ve kesişim değeri $(\alpha)$ eşitlik Eşitlik 3 yardımıyla hesaplanabilmektedir. Bu eşitliklerde, $\bar{x}$ ve $\bar{y}$ bağımsız değişkenlerin aritmetik ortalamalarını ifade etmektedir. Yapılan uygulamada, $X$ bağımsız değişkeni konut sayısını, $Y$ bağımlı değişkeniyse ilgili ulaşım hattından geçen motorlu araç sayını göstermektedir. Tablo 2'de belirtilen ulaşım hatlarındaki yıllık bazda ortalama günlük araç sayıları, Tablo 3'te

\begin{tabular}{|c|c|c|c|c|c|c|c|c|c|c|c|c|}
\hline \multirow{2}{*}{$\begin{array}{c}\text { Ulaşım } \\
\text { Hattı İsmi }\end{array}$} & \multirow{2}{*}{$\begin{array}{c}\text { Ulaşım } \\
\text { Hattı } \\
\text { Uzunluğ } \\
\text { u [km] }\end{array}$} & \multirow{2}{*}{$\begin{array}{l}\text { Seçilen Konut } \\
\text { Bölgesi }\end{array}$} & \multicolumn{10}{|c|}{ Toplam Yıllık Ortalama Günlük Taşıt Sayısı } \\
\hline & & & 2005 & 2006 & 2007 & 2008 & 2009 & 2010 & 2011 & 2012 & 2013 & 2014 \\
\hline $\begin{array}{l}\text { Silivri- } \\
\text { Selimpaşa }\end{array}$ & 12,1 & Silivri & 1525 & 1792 & 2025 & 2092 & 1870 & 2438 & 1844 & 1712 & 1289 & 1670 \\
\hline $\begin{array}{l}\text { Selimpaşa- } \\
\text { Kumburgaz- } \\
\text { Çatalca- } \\
\text { Hadımköy }\end{array}$ & 26,8 & Büyükçekmece & 10360 & 12093 & 13406 & 13796 & 13457 & 14073 & 15199 & 15533 & 15398 & 15119 \\
\hline $\begin{array}{l}\text { Hadımköy- } \\
\text { Avcılar }\end{array}$ & 6,0 & $\begin{array}{l}\text { Avcılar- } \\
\text { Beylikdüzü- } \\
\text { Esenyurt }\end{array}$ & 19409 & 20641 & 23292 & 23455 & 23555 & 24531 & 32341 & 28097 & 24668 & 58122 \\
\hline $\begin{array}{l}\text { Avcilar - } \\
\text { Mahmutbey }\end{array}$ & 14,1 & $\begin{array}{c}\text { Bağcılar- } \\
\text { Başakşehir- } \\
\text { Küçük Çekmece }\end{array}$ & 47828 & 52964 & 57263 & 57783 & 60253 & 63942 & 66574 & 72647 & 81397 & 50390 \\
\hline $\begin{array}{l}\text { Çamlıca- } \\
\text { Samandıra }\end{array}$ & 7,0 & $\begin{array}{l}\text { Ümraniye- } \\
\text { Sancaktepe- } \\
\text { Çekmeköy }\end{array}$ & 18293 & 24922 & 28017 & 35370 & 35416 & 32417 & 31888 & 38176 & 33866 & 22579 \\
\hline $\begin{array}{l}\text { Samandira- } \\
\text { Kurtköy }\end{array}$ & 12,1 & $\begin{array}{c}\text { Sultanbeyli- } \\
\text { Pendik }\end{array}$ & 7493 & 12100 & 14235 & 17235 & 21205 & 26265 & 28314 & 28933 & 29873 & 46347 \\
\hline $\begin{array}{l}\text { Kurtköy- } \\
\text { Şekerpinarı }\end{array}$ & 9,4 & Tuzla & 15159 & 18863 & 22095 & 23006 & 22560 & 22612 & 25269 & 27247 & 30141 & 30640 \\
\hline
\end{tabular}
ise seçilen bölgelerdeki oturma izni alınan konut sayıları listelenmiştir.

Tablo 2. Ulaşım hatlarındaki yıl bazında ortalama günlük araç sayıları [33] 
Tablo 3. Seçilen konut bölgelerine ait 2004-2014 yılları arasındaki konut sayıları [35]

\begin{tabular}{|l|c|c|c|c|c|c|c|c|c|c|}
\hline \multirow{2}{*}{ Konut Bölgesi } & \multicolumn{9}{|c|}{ Yllar } \\
\cline { 2 - 12 } & $\mathbf{2 0 0 5}$ & $\mathbf{2 0 0 6}$ & $\mathbf{2 0 0 7}$ & $\mathbf{2 0 0 8}$ & $\mathbf{2 0 0 9}$ & $\mathbf{2 0 1 0}$ & $\mathbf{2 0 1 1}$ & $\mathbf{2 0 1 2}$ & $\mathbf{2 0 1 3}$ & $\mathbf{2 0 1 4}$ \\
\hline Silivri & 645 & 480 & 949 & 943 & 1876 & 1489 & 1469 & 4099 & 1433 & 1416 \\
\hline Büyükçekmece & 356 & 760 & 191 & 1167 & 3093 & 1610 & 2252 & 3413 & 2805 & 3556 \\
\hline $\begin{array}{l}\text { Avcrlar-Beylikdüzü- } \\
\text { Esenyurt }\end{array}$ & 1811 & 420 & 1015 & 747 & 3727 & 2883 & 17213 & 15720 & 28826 & 36809 \\
\hline $\begin{array}{l}\text { Bağcrlar-Başakşehir- } \\
\text { Küçükçekmece }\end{array}$ & 1834 & 7212 & 1800 & 7326 & 7364 & 11420 & 23308 & 19643 & 23141 & 18409 \\
\hline $\begin{array}{l}\text { Ümraniye-Sancaktepe- } \\
\text { Çekmeköy }\end{array}$ & 789 & 812 & 659 & 3341 & 5692 & 5517 & 7377 & 8284 & 15200 & 18268 \\
\hline Sultanbeyli-Pendik & 65 & 852 & 3831 & 626 & 1897 & 2801 & 8752 & 1220 & 6954 & 8695 \\
\hline Tuzla & 107 & 36 & 132 & 419 & 2209 & 3320 & 3709 & 2579 & 3794 & 3264 \\
\hline
\end{tabular}

\section{BULGULAR VE TARTIŞMA}

Seçilen her bir konut bölgesindeki (Tablo 3) konut sayısı ile konut bölgesini etkileyen ulaşım hattındaki araç sayısı (Tablo 2) arasındaki ilişki regresyon analizleriyle belirlenmiştir. Analizler sonucu her bir konut bölgesi ile ulaşım hattına ait korelasyon katsayısı ve regresyon denklemleri Tablo 4'te sunulmuştur.

Tablo 4. Analiz sonucu elde edilen korelasyon kat sayıları ve regresyon denklemleri

\begin{tabular}{|l|c|c|c|}
\hline \multicolumn{1}{|c|}{ Konut Bölgesi } & Ana Ulaşım Ağı \\
Bölgesi & $\begin{array}{c}\text { Korelasyon } \\
\text { ve Belirlilik } \\
\text { Katsayıları } \\
\left(\mathbf{r} \text { ve R } \mathbf{R}^{2}\right.\end{array}$ & $\begin{array}{c}\text { Regresyon Denklemi } \\
Y=\beta . X+\alpha+\varepsilon\end{array}$ \\
\hline Silivri & Silivri-Selimpaşa & $\begin{array}{c}\mathrm{r}=-0,0700 \\
\mathrm{R}^{2}=0,0049\end{array}$ & $\mathrm{y}=-0,0219 \mathrm{x}+1858,2$ \\
\hline Büyükçekmece & $\begin{array}{c}\text { Selimpaşa-Kumburgaz- } \\
\text { Çatalca-Hadımköy }\end{array}$ & $\begin{array}{c}\mathrm{r}=0,7519 \\
\mathrm{R}^{2}=0,5654 \\
\mathrm{r}=0,7910 \\
\mathrm{R}^{2}=0,6257\end{array}$ & $\mathrm{y}=0,9701 \mathrm{x}+11981$ \\
\hline Avcılar-Beylikdüzü-Esenyurt & Hadımköy-Avcılar & $\mathrm{y}=0,6750 \mathrm{x}+20442$ \\
\hline Bağcılar-Başakşehir-Küçük & Avcılar-Mahmutbey & $\begin{array}{c}\mathrm{r}=0,6925 \\
\mathrm{R}^{2}=0,4796\end{array}$ & $\mathrm{y}=0,8611 \mathrm{x}+50645$ \\
\hline Ümraniye-Sancaktepe-Çekmeköy & Çamlıca-Samandıra & $\begin{array}{c}\mathrm{r}=0,1319 \\
\mathrm{R}^{2}=0,0174\end{array}$ & $\mathrm{y}=0,1401 \mathrm{x}+29170$ \\
\hline Sultanbeyli-Pendik & Samandıra-Kurtköy & $\begin{array}{c}\mathrm{r}=0,7506 \\
\mathrm{R}^{2}=0,5634\end{array}$ & $\mathrm{y}=2,5092 \mathrm{x}+14244$ \\
\hline Tuzla & Kurtköy-Şekerpınarı & $\begin{array}{c}\mathrm{r}=0,7671 \\
\mathrm{R}^{2}=0,5884\end{array}$ & $\mathrm{y}=2,2853 \mathrm{x}+19287$ \\
\hline
\end{tabular}

Her bir konut bölgesi ile bu bölgeden geçen araç sayısı arasındaki doğrusal ilişkiler, Şekil 5'te grafiklerde gösterilmiştir. Grafikler incelendiğinde Silivri konut bölgesi ile Silivri-Selimpaşa ana ulaşım hattındaki trafik yoğunluğu arasında neredeyse bir ilişkinin olmadığı $(r=-0,0700)$ görülmektedir. (Şekil 5a). Büyükçekmece konut bölgesi ile Selimpaşa-Kumburgaz-Çatalca-Hadımköy ana ulaşım hattındaki trafik yoğunluğu arasında pozitif yönde yüksek bir ilişki $(r=0,7519)$ vardır (Şekil 5b). Avcılar-Beylikdüzü-Esenyurt konut bölgesi ile Hadımköy-Avcılar ana ulaşım hattındaki trafik yoğunluğu arasında pozitif yönde yüksek bir ilişki $(r=0,7910)$ vardır (Şekil 5c). Bağcılar-Başakşehir-Küçükçekmece konut bölgesi ile Avcılar-Mahmutbey ana ulaşım hattındaki trafik yoğunluğu arasında pozitif yönde orta bir ilişki $(r=0,6925)$ vardır (Şekil 5d). ÜmraniyeSancaktepe-Çekmeköy konut bölgesi ile Çamlıca-Samandıra ana ulaşım hattındaki trafik yoğunluğu arasında neredeyse bir ilişki $(r=0,1319)$ yoktur (Şekil 5e). Sultanbeyli-Pendik konut bölgesi ile Samandıra-Kurtköy ana ulaşım hattındaki trafik yoğunluğu arasında pozitif yönde yüksek bir ilişki ( $r=0,7506)$ vardır (Şekil 5f). Tuzla konut bölgesi ile Kurtköy-Şekerpınarı ana ulaşım hattındaki trafik yoğunluğu arasında pozitif yönde yüksek bir ilişki $(\mathrm{r}=0,7671)$ vardır (Şekil 5g). 
Silivri Bölgesindeki Konut Sayısı ile Araç Sayısı Arasındaki İlişki

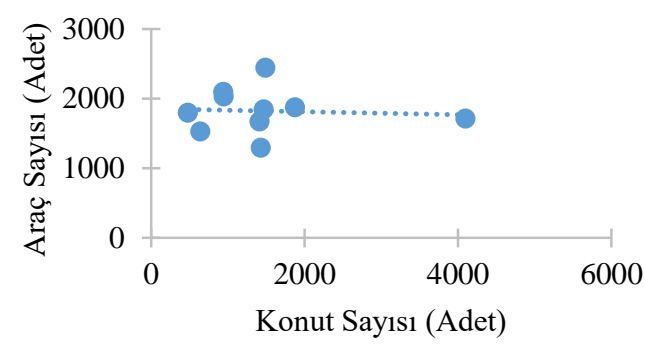

(a)

Avcılar-Beylikdüzü-Esenyurt Bölgesindeki

Konut Sayısı ile Araç Sayısı Arasındaki İlişki

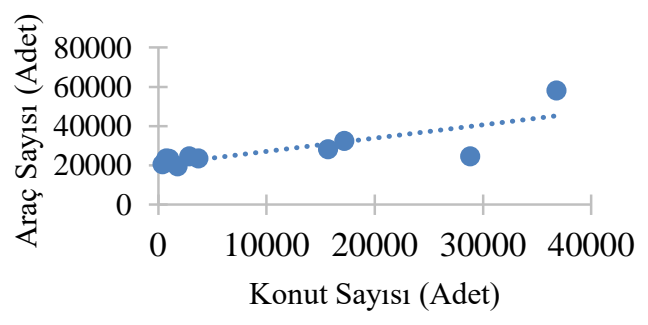

(c)

Ümraniye-Sancaktepe-Çekmeköy Bölgesindeki Konut Sayısı ile Araç Sayısı Arasındaki İlişki

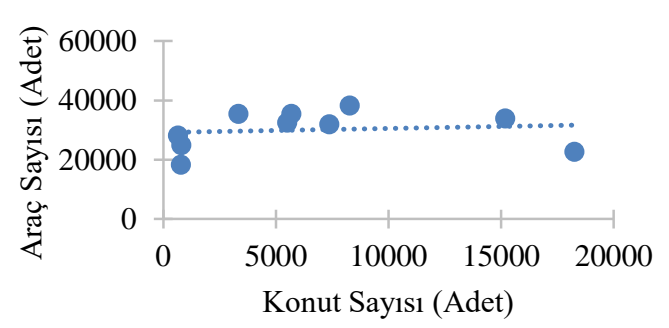

(e)
Büyükçekmece Bölgesindeki Konut Sayısı ile Araç Sayısı Arasındaki İlişki

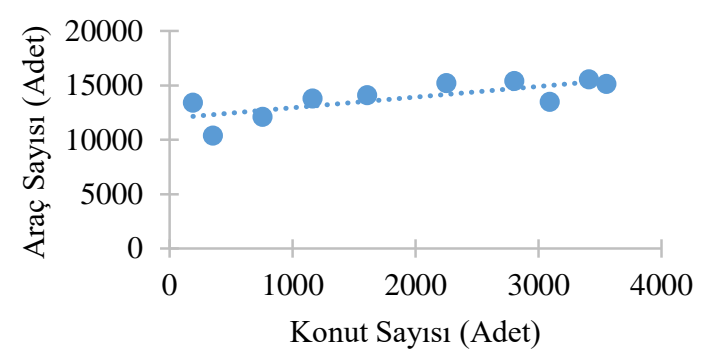

(b)

Bağcılar-Başakşehir-Küçükçekmece Bölgesindeki Konut Sayısı ile Araç Sayısı Arasındaki İlişki

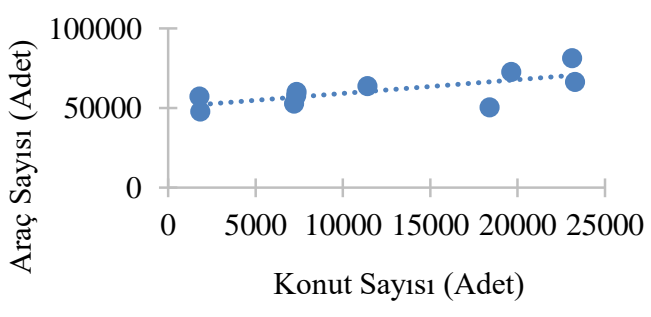

(d)

Sultanbeyli-Pendik Bölgesindeki Konut Sayısı ile Araç Sayısı Arasındaki İlişki

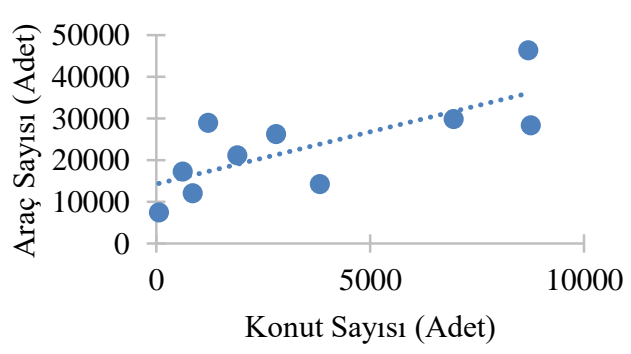

(f)

Tuzla Bölgesindeki Konut Sayısı ile Araç Sayısı Arasındaki İlişki

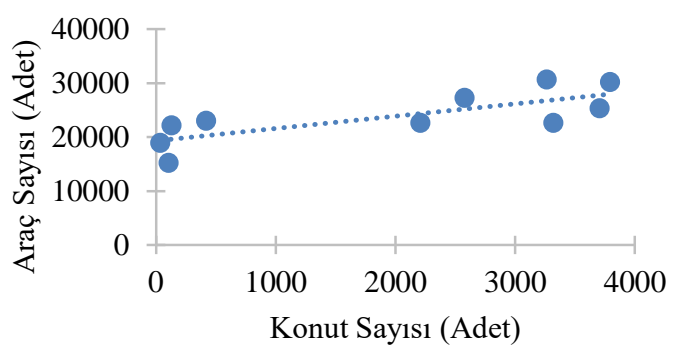

(g)

Şekil 5. Konut bölgelerindeki konut sayıları ile araç sayıları arasındaki ilişkiler. 


\section{SONUÇLAR}

Konut amaçlı arazi kullanımında zaman içerisinde gerçekleşen gelişim ve değişimler, kişilerin farklı mekanlar arası (Ör. Ev-İş, Ev-Okul) ulaşımlarını doğrudan etkilemektedir. Kentsel büyümeye bağlı olarak artan konut sayısı büyük kentlerde trafik yoğunluğunu da beraberinde getirmektedir. Türkiye'de kentsel büyümenin en yoğun olarak yaşandığı şehir olan İstanbul'da artan konut sayısına bağlı olarak ana ulaşım ağlarında trafik yoğunluğu görülmektedir. Bu çalışmada yapılan regresyon analizleri sonucunda Silivri bölgesi hariç diğer konut bölgelerinde pozitif yönde ve güçlü bir ilişki olduğu ispatlanmıştır. Silivri bölgesindeki negatif korelasyonun sebebinin artan konut sayısından ziyade bölgedeki tatil amaçlı (Gülük) trafik yoğunluğun varlığıdır. Grafikler incelendiğinde Avrupa yakasında özellikle Büyükçekmece, Beylikdüzü, Esenyurt ve Avcılar ilçelerindeki kentsel yayılmaya bağlı olarak artan konutlaşmanın beraberinde trafik yoğunluğunu da getirdiği gözlemlenmektedir. Anadolu yakasında ise Sultanbeyli, Pendik ve Tuzla ilçelerinde son yıllardaki artan konutlaşmaya bağlı olarak bu ilçeleri etkileyen ana ulaşım hatlarında trafik yoğunluğunda artış olduğu sonucuna varılmıştır.

Kentsel büyümenin ağırlıklı olarak doğu ve batı yönlerine doğru gerçekleştiği İstanbul'da kontrolsüz şekilde artan nüfusa ve yetersiz altyapı koşullarına bağlı olarak trafik yoğunluğunun daha da artması öngörülebilir. Bu bağlamda, İstanbul kent içi ulaşımının temel belirleyicisi konumundaki arazi kullanım planlaması, ulaşım sistemleri ve seçenekleri ile bir bütünlük oluşturacak düzen ve anlayış ile ele alınmalıdır. İstanbul'un hızlı büyüyen ilçelerine yönelik olarak geliştirilen çözümlerde, ilçelerin ve çevre yerleşimlerinin nüfus ve işgücü potansiyelleri dikkate alınarak konut-işyeri ilişkileri kurulabilmelidir. Bu bağlamda ulaşım ihtiyacını meydana getiren etkenlerin sistemli analizi gerekli olmaktadır. Sürdürülebilir bir kentsel büyümenin önemli bir evresi olan bütünleşik bir konut-ulaşım planlaması için gerekli olan konut-ulaşım ilişsisi (her bir konut bölgesi için) elde edilen regresyon denklemleri yardımı ile tahmin edilebilir.

\section{KAYNAKLAR}

[1] ADIGÜZEL, F., TOROĞLU, E., KAYA, Ö., "Kentsel Gelişme ile Ulaşım İlişkisi: Adana Örneği”, Turkish Studies, 10 (6), 27-46, 2015.

[2] SUDHIRA, H.S., RAMACHANDRA, T.V., JAGADISH, K.S, "Urban Sprawl: Metrics, Dynamics and Modelling Using GIS”, International Journal of Applied Earth Observation and Geoinformation, 5, 29-39, doi:10.1016/j.jag.2003.08.002, 2004.

[3] BANISTER, D., "The Sustainable Mobility Paradigm”, Transport Policy, 15 (1), 73- 83, 2008.

[4] PALOMARES, J.C.G., "Urban Sprawl and Travel to Work: the Case of the Metropolitan Area of Madrid", Journal of Transport Geography, 18, 197-213, 2010.

[5] BRUECKNER, J.K., LARGEY, A.G., "Social Interaction and Urban Sprawl", Journal of Urban Economics, 64, 18-34, doi:10.1016/j.jue.2007.08.002, 2007.

[6] BRINCKERHOFF, P., "Land Use Impacts of Transportation: A Guidebook", National Academy Press, Washington, D.C., America, 1999.

[7] KEÇELİ, A., KARAKUYU, M., "Bağlantı Yolları Üzerindeki Trafik Yoğunluğunda Yakın Çevre Arazi Kullanımı Etkisinin CBS Tabanlı Analizi: Hadımköy-Beylikdüzü Bağlantı Yolu Örneği”, TMMOB Harita ve Kadastro Mühendisleri Odas1, Ulusal Coğrafi Bilgi Sistemleri Kongresi, 1-9, Trabzon, Türkiye, 2007.

[8] ATIŞ, T., "Kentsel Saçak-Sanayi Dinamiği ve Ulasım İliskisi: Beylikdüzü Organize Sanayi Bölgesi Örneği”, Yüksek Lisans Tezi, İTÜ Fen Bilimleri Enstitüsü, İstanbul, Türkiye 2003.

[9] ÖZALP, M., “Türkiye'de Kentsel Ulaşım Planlaması Çalışmalarında Benimsenen Yaklaşımlar; Sorunlar ve Çözüm Önerileri”, Yüksek Lisans Tezi, Gazi Üniversitesi, Fen Bilimleri Enstitüsü, Ankara, Türkiye, 2007.

[10] FIRAT, A.S., "Kent İçi Ulaşım Konusunda Belediyelerce Yürütülen Düzenlemeler ve Yaşanan Sorunlar”, IV. Ulaşım ve Trafik Kongresi - Sergisi, 26-27, Ankara, Türkiye, 2003.

[11] TOPRAK, R., AKTÜRK, N., "Raylı Ulaşım Sistemlerinin Çevresel Etkileri ve Gürültü” IV. Ulaşım Ve Trafik Kongresi - Sergisi, 33-38, Ankara, Türkiye, 2003.

[12] UYSAL, C., "Detection of Urban Expansion In Turkey by Using Spectrally Unmixed Landsat Images and Nighttime DMSP-OLS Images", Ph.D. Thesis, Istanbul Technical University, Graduate School of Science Engineering and Technology, İstanbul, Turkey, 2015.

[13] TOMTOM Traffic Index - Measuring Congestion Worldwide, https://www.tomtom.com/tr_tr/trafficindex/\#/list (erişim tarihi 02.01.2016).

[14] KALELIOĞLU, M.R., ÖZGÜR, E.M., "İkametgâh Memnuniyeti Bağlamında Konut Yeri Seçimi ve İkametgâh Hareketliliği: Bolu Kenti Örneği”, Coğrafi Bilimler Dergisi, 11(2), 149-168, 2013. 
[15] AKSEKİ, H., MEŞHUR, M., Ç., “An Analysis of the Konya's Urbanized Fertile Agricultural Lands and Urban Sprawl”, MEGARON, 8 (3), 165-174, 2013.

[16] MCINTYRE, N., KNOWLES-YANEZ, K., HOPE, D., "Urban Ecology as an Interdisciplinary Field: Differences in the use of 'Urban' Between the Social and Natural Science”, Urban Ecosystems, 4, 5-24, 2000.

[17] TOSUN, E.K, "Sürdürülebilir Kentsel Gelişim Sürecinde Kompakt Kent Modelinin Analizi”, Yönetim ve Ekonomi Dergisi, 20 (1), 31-46, 2013.

[18] ANAS, A., PINES, D., “Anti-sprawl Policies in a System of Congested Cities", Regional Science and Urban Economics, 38, 408-423, doi:10.1016/j.regsciurbeco.2008.05.001, 2008.

[19] TRAVISI, C.M., CAMAGNI, R., NIJKAMP, P., "Impacts of Urban Sprawl and Commuting: a Modelling Study for Italy", Journal of Transport Geography, 18, 382-392, doi:10.1016/j.jtrangeo.2009.08.008, 2010.

[20] AYAZLI, İ.E., BATUK, F., DEMIR., H., "Kentsel Yayılma Simülasyon Modelleri Ve Hücresel Otomat", TMMOB Harita ve Kadastro Mühendisleri Odas1, 13. Türkiye Harita Bilimsel ve Teknik Kurultayı 1-7, Ankara, Türkiye, 2011.

[21] CLARKE K.C., HOPPEN, S., GAYDOS, L., “A Self Modifying Cellular Automaton Model of Historical Urbanization in the San Francisco Bay Area”, Environment and Planning B: Planning and Design, 24, 2472, 1997.

[22] CHENG, J., "Modelling Spatial \& Temporal Urban Growth”, Doktora Tezi, Utrecht Universitesi, Coğrafya Bilimleri Fakültesi, Utrecht, Hollanda, 2003.

[23] PORTUGALI, J., "Complex Artificial Environments: Simulation, Cognition and VR in the Study and Planning of Cities", Springer-Verlag Berlin Heidelberg, 10.1007/3-540-29710-3, 2006.

[24] EWING, R., PENDALL, R., CHEN, D., "Measuring Sprawl and Its Impact, Smart Growth America" https://www.smartgrowthamerica.org/app/legacy/documents/MeasuringSprawl.PDF (erişim tarihi 03.05.2016).

[25] ARBURY, J., "From Urban Sprawl to Compact City - An Analysis of Urban Growth Management in Auckland" http://www.greaterauckland.org.nz/wp-content/uploads/2009/06/thesis.pdf, (erişim tarihi 23.05.2016).

[26] SHERMAN, R.A., "A Private Ownership Bias in Transit Choice” American Economic Review, 57, 12111217, 1967.

[27] ERTÜRK, H., "Kent İçi Ulaşım; Trafik Tıkanıklığının Ekonomik Analizi ve Yeni Yaklaşımlar”, Kentli Dergisi, 2 (6), 46-51, 2012.

[28] İSTANBUL'UN YERLEŞKESI VE YAPISI, http://www.istanbul.gov.tr/Files/ebulten/2016-9/ icerikyerlesim.html (erişim tarihi 02.01.2016).

[29] REZIDANSLAR VE TRAFIK SORUNU, http://gusam.org/rezidanslar-ve-trafik-sorunu/ (erişim tarihi 22.01.2016).

[30] KEÇELİ, A., KARAKUYU, M., "Hadımköy-Beylikdüzü Bağlantı Yolu Üzerindeki Trafik Sıkışıklığı Probleminin Nedenleri ve Çözüm Yolları”, Elektronik Sosyal Bilimler Dergisi, 7(23), 116-133, 2008.

[31] KONUT İSTATİSTIKLERİ, http://www.tuik.gov.tr/Start.do (erişim tarihi 03.01.2016).

[32] VECDİ DİKER ÇALIŞMA GRUBU, "İstanbul'un Ulaşım ve trafik Sorunu-Üçüncü Çevre Yolu ve Boğaz Geçişi”, http://www.imo.org.tr/resimler/ekutuphane/pdf/3090.pdf (erişim tarihi 21.03.2016).

[33] KARAYOLLARI ULAŞIM İSTATISTIKLERİ, http://www.kgm.gov.tr/Sayfalar/KGM/SiteTr/Istatistikler/ TrafikveUlasim.aspx (erişim tarihi 04.01.2016). adresinden erişildi.

[34] KORELASYON VE REGRESYON ANALİİ, http://www.toraks.org.tr/mse-ppt-pdf/Kenan_KOSE3.pdf (erişim tarihi 25.01.2016).

[35] TUİK, İstatistiklerle Türkiye, http://www.tuik.gov.tr/Start.do (erişim tarihi 25.02.2016).

[36] TEZER, A., "Kentsel ulaşım planlamasında (KUP) arazi kullanımı-ulaşım etkileşiminin modellenmesi: İstanbul üzerine bir değerlendirme", Doktora Tezi, İstanbul Teknik Üniversitesi, Fen Bilimleri Enstitüsü, İstanbul, Türkiye, 1997. 